\title{
Mediators of Effects of Cooperative Learning on Prosocial Behavior in Middle School
}

\author{
Mark J. Van Ryzin ${ }^{1}$ (D) Cary J. Roseth ${ }^{2} \cdot$ Anthony Biglan ${ }^{1}$
}

Accepted: 29 January 2020 / Published online: 6 February 2020

(C) Springer Nature Switzerland AG 2020

\begin{abstract}
In this study, we tested the effects of cooperative learning on students' prosocial behavior. Cooperative learning is a small-group instructional technique that establishes positive interdependence among students and, unlike most current school-based programs, does not mandate a formal curriculum. Given the emphasis in cooperative learning on peer reinforcement for positive and helpful behavior during learning activities, we hypothesized that cooperative learning would promote higher levels of prosocial behavior, and that these effects would be mediated by peer relatedness. Using a sample of 1890 students (47.1\% female, $75.2 \%$ White) from a cluster randomized trial of 15 middle schools, we found that cooperative learning significantly enhanced prosocial behavior across two years. Mediation was only partial, however, suggesting that additional mechanisms were at work, such as changes to social norms or teacher behavior. Given that cooperative learning has been shown to enhance student engagement and academic achievement in prior research, we argue that cooperative learning should be a central component of teacher training and professional development.
\end{abstract}

Keywords Cooperative learning $\cdot$ Prosocial behavior $\cdot$ Peer relations $\cdot$ Prevention $\cdot$ Middle school

Antisocial behavior has been characterized as manipulative and deceitful, lacking in empathy, impulsive, aggressive, and irresponsible (Farrington 2005). Research suggests that the most common forms of antisocial behavior in secondary schools are bullying and fighting, with anywhere from a quarter to a third of students reporting being bullied by peers (Craig et al. 2009; Pool et al. 2017; World Health Organization 2012). Fortunately, some progress has been made in developing school-based prevention programs, with meta-analyses of curriculum-based anti-bullying programs finding

Mark J. Van Ryzin

markv@ori.org

1 Oregon Research Institute, 1776 Millrace, Eugene, OR 97403, USA

2 Michigan State University, East Lansing, MI, USA 
small but significant effects (Ferguson et al. 2007; Merrell et al. 2008; Ttofi and Farrington 2011).

In contrast, prosociality consists of a broad constellation of attitudes, values, and behaviors that involve cooperating with and sacrificing for others (Wilson 2007), which contrasts with more self-aggrandizing or self-centered values, goals, and behavior. The development of prosocial behavior is not only a means to suppress antisocial behavior (Caprara et al. 2014; Schwartz et al. 2010), but is foundational for the ongoing existence of any community of people. Prosocial behavior has been a key aspect of human evolution (Wilson 2007, 2002) and was selected during our evolutionary history when groups that contained cooperative people, committed to the wellbeing of those around them, were more successful (Roseth 2016; Wilson 2015). Thus, developing prosocial, cooperative behaviors among young people can be thought of as both a natural extension of our evolutionary history as well as a critical aspect of maintaining functional communities, particularly communities of students and teachers (Biglan 2015).

Existing school-based approaches to encouraging prosocial behavior are largely in the domain of social-emotional learning (SEL) programs, which are designed to promote social competencies among children and youth. These programs are generally curriculum-driven and typically include direct instruction and role playing in SEL skills, such as goal setting, perspective taking, interpersonal problem solving, and decision making; some programs may also include components aimed at aspects of the school climate, such as the teacher-student relationship. Recent meta-analyses have found that these programs have small to moderate effects on SEL skills (ES =.57 in Durlak et al. 2011; ES =.23 in Taylor et al. 2017), as well as small effects on positive social behavior (ES $=.24$ in Durlak et al. 2011; ES =.13 in Taylor et al. 2017).

\section{A Different Approach}

In this study, we tested a different approach that strives to promote prosocial, nurturing behavior among students during daily instruction rather than as a separate activity that stands apart from the existing curriculum. Our approach asked teachers to increase opportunities for positive peer interaction through carefully structured small-group learning activities that provided reinforcement for cooperative, prosocial behavior among students.

To ensure that these group-based learning activities had the desired effect, they had to contain certain design elements to address the potential for negative social dynamics in learning groups (Johnson and Johnson 1989). Specifically, social psychological research on peer interaction demonstrates that imposing social contact among students who belong to different social groups can actually exacerbate perceived differences by reinforcing and strengthening the latent competitive dynamic underlying in- and outgroup perceptions (Dovidio et al. 2009; Pettigrew and Tropp 2000). In order for smallgroup instruction to promote cooperative behavior within learning groups, the social context must be structured to promote the breakdown of biases and prejudices among students who belong to different social groups or are perceived to have different social status (Pettigrew 1998; Pettigrew and Tropp 2008). 
According to Social Interdependence Theory (Deutsch 1949, 1962), the key ingredient for creating such a social context is positive interdependence, where goal structures are aligned such that individual goal attainment is enhanced when others in the group also reach their own goals. In situations of positive interdependence, individuals are incentivized to promote the success of one another (Johnson et al. 1983). When goals are structured to promote positive interdependence, students are rewarded and reinforced for interacting in ways that promote joint goal attainment, such as helping each other and sharing information and resources. The positive feelings that arise from collective goal achievement tend to be transferred to the group members who promote one's success, resulting in a positive feedback loop that further promotes interpersonal attraction and acceptance (Johnson et al. 2014). Indeed, theory and research on social interaction suggests that gains in social skills alone are insufficient to overcome biases and prejudices; only positive interdependence (and the subsequent positive social interactions that arise from it) can motivate youth to re-evaluate previous conclusions regarding the social desirability of others (Allport 1954; Bierman 2004).

\section{Cooperative Learning}

Cooperative learning is one of the few empirically supported instructional approaches that specifies the establishment of positive interdependence in small-group learning activities. Small-group instruction has been in existence for decades, and is sometimes practiced under the names of peer learning (Topping 2005) or active learning (Silberman 1996), but herein will be referred to as cooperative learning to align with our guiding framework (i.e., Johnson and Johnson 1989; Johnson et al. 2013). Cooperative learning is an umbrella term that includes reciprocal teaching, peer tutoring, jigsaw, and other group-based activities in which teachers establish positive interdependence in small learning groups of two to four students. In a jigsaw lesson, for example, each student in a learning group is given responsibility for a portion of the overall content of the lesson (Aronson and Bridgeman 1979). The student must learn their portion of the content and, in collaboration with other students who have been assigned the same content, the student must prepare materials to use when teaching the content to the other students in their group. In this way, all the students in the group are exposed to all of the lesson content. Teachers can enhance interdependence by offering rewards or bonuses to the groups whose members all attain a certain degree of success on a post-lesson assessment, such as a quiz or essay.

In a cooperative learning lesson, many different types of positive interdependence may exist (Johnson and Johnson 1989). For example, teachers may require a single finished product from a group (goal interdependence), or may offer a reward to the group if everyone achieves above a certain threshold on an end-of-unit assessment (reward interdependence). The lesson plan may require that each member of the group be issued different materials that they must share with others in their group to complete the lesson (resource interdependence), or that each member of the group must fulfill a different role (role interdependence, e.g., tracking the group status, or taking notes on group discussions) or complete a unique task (task interdependence, e.g., each student has a different component of a project or presentation) for a lesson to be completed successfully. In all these examples, positive interdependence can be strengthened when 
groups have their own name or symbol (identity interdependence). Different forms of positive interdependence can be layered upon one another in a single lesson, increasing the incentive for students to collaborate.

In addition to positive interdependence, however, these group-based learning activities must also provide individual accountability to ensure that students have a strong incentive to contribute to the success of the group (Johnson and Johnson 1989). Individual accountability can include an end-of-unit assessment to be taken individually (with the potential for group rewards as discussed above), or something as simple as a random oral quiz by the teacher as he or she supervises the group work during class time. Finally, a high-quality cooperative learning lesson should include three additional factors: (1) Explicit coaching in collaborative social skills (e.g., encouraging participation, checking for understanding, sharing ideas, asking for clarification), which includes setting expectations for group behavior and monitoring by the teacher to identify and reward examples of such behavior; (2) A high degree of face-to-face interaction, with the group sitting together, facing one another, and isolated (to a degree) from other groups in the classroom; and, (3) Guided processing of group performance after the lesson is completed, in which the group discusses what they did well, sets targets for improvement in the future, and provides one another with positive reinforcement for behavior during the lesson that contributed to group success (Johnson et al. 2013).

A great deal of research has found that cooperative learning has robust positive effects on interpersonal attraction, social acceptance, motivation, and academic achievement across all grade levels and school subjects (Ginsburg-Block et al. 2006; Johnson and Johnson 1989, 2005; Johnson et al. 2014). For example, in a meta-analysis of 148 studies representing over 17,000 early adolescents, cooperative learning was associated with greater achievement $(\mathrm{ES}=.46$ when compared to competitive goal structures, and $\mathrm{ES}=.55$ when compared to individualistic goal structures) and more positive peer relationships ( $\mathrm{ES}=.48$ when compared to competitive goal structures, and $\mathrm{ES}=.42$ when compared to individualistic goal structures; Roseth et al. 2008). Cooperative learning has also been found to have moderate to large effects on student behavior, including reductions in victimization, bullying, and alcohol and tobacco use (Van Ryzin and Roseth 2018a, b, c).

By bringing about more positive peer relations, cooperative learning also opens the door to inducibility, which is defined as an openness to being influenced by others (Deutsch 1949). Specifically, positive relationships provide the mechanism by which peer pressure can be applied to increase cooperative behavior (or limit uncooperative behavior). In cooperative learning lessons, where interdependent goals and rewards are established, this peer pressure is believed to be particularly powerful in guiding individual behavior (Johnson 2003).

In addition, cooperative learning calls for teachers to continually reinforce positive, cooperative behavior among students. For example, teachers are trained to reinforce the use of positive social skills in learning groups by observing student interactions during learning activities and recording the number of times students exhibit various kinds of positive, helpful behavior (Johnson et al. 2013). Teachers are also trained to instruct students to find something specific and positive to say about each group member's contribution to the group performance, 
which is intended to encourage students to reinforce one another's positive, prosocial behavior.

\section{Current Study}

To date, however, cooperative learning has not yet been formally tested as a mechanism to encourage greater levels of prosocial behavior. Thus, in this study, we evaluated the Johnsons' approach to cooperative learning (Johnson et al. 2013) as an intervention to promote prosocial behavior in middle school. We also wished to explore mediators of effects, i.e., whether peer support and encouragement (captured in terms of peer relatedness) mediated intervention effects on prosocial behavior. Our hypotheses were as follows:

1. The positive support and encouragement from peers that is central to cooperative learning will create more positive peer relations; and,

2. More positive peer relations will, in turn, contribute to higher levels of prosocial behavior.

\section{Method}

All aspects of this study were approved by the Institutional Review Board (IRB) at the Oregon Research Institute.

\subsection{Sample}

The sample was derived from a small-scale randomized trial of cooperative learning in 15 rural middle schools in the Pacific Northwest. Schools were matched based upon size and demographics (e.g., free/reduced lunch percentage) and randomized to condition (intervention vs. waitlist control). We were concerned about the likelihood of losing schools assigned as controls, so we randomized an extra school to this condition; thus, we had 8 waitlist-control and 7 intervention schools.

Our analytic sample included $N=1890$ students who enrolled in the project during the 2016-2017 or 2017-2018 school years (we surveyed 7th graders in the first year, and followed these students into 8 th grade in the following year). We achieved greater than $80 \%$ student participation at each data collection point by using a passive consent procedure and providing research staff to oversee the data collection. We also offered compensation to the schools and teachers for participating in the project, and enrolled participating students in a prize raffle. Student demographics by school are reported in Table 1. Overall, the sample was $47.1 \%$ female $(N=890)$ and $75.2 \%$ White $(N=1421)$. Other racial/ethnic groups included Hispanic/Latino $(13.2 \%, N=249)$, multi-racial $(5.3 \%, N=100)$, and American Indian/Alaska Native $(3.1 \%, N=58)$; our sample included less than $1 \%$ Asian, African-American, and Native Hawaiian/Pacific Islander. Overall, 13.9\% $(N=262)$ were reported as having Special Education status, $78.6 \%$ $(N=1486)$ did not have Special Education status, and $7.5 \%(N=142)$ were missing this designation. Free and reduced-price lunch (FRPL) status was not made available by the 
schools, although school-level FRPL figures (obtained from state records) are reported in Table 1.

\subsection{Procedure}

Training for intervention school staff began in the fall of 2016 and continued throughout the 2016-2017 school year, consisting of 3 half-day in-person sessions, periodic check-ins via videoconference, and access to resources (e.g., newsletters). The three half-day group-based in-person training sessions were conducted in (1) late September and early October, (2) late October through early December, and (3) late January through late March. We also had a half-day follow-up teacher training during the fall of the 2017-2018 school year. Due to the geographic dispersal of the schools, each school received training individually according to their own schedule for professional development. Finally, we conducted a one-day administrator training during the summer of 2017.

Teacher training sessions were conducted by D. W. and R. T. Johnson, supported by the first two authors, and utilized Cooperation in the Classroom, 9th Edition by Johnson et al. (2013); each staff member was given a copy of the book. During the training, teachers were given information regarding the theoretical foundation for cooperative learning, including the concepts of positive interdependence, individual accountability, group social skills, face-to-face interaction, and group processing (as discussed in the Introduction). The training was not provided in a lecture format; rather, teachers were trained in cooperative learning through the use of cooperative learning techniques. For example, teachers participated in jigsaw lessons, where they learned

Table 1 Descriptive data by school

\begin{tabular}{lllllll}
\hline School & Intervention & $\mathrm{N}$ & $\%$ female & $\%$ White & \% Special Ed & $\%$ FRPL $^{\mathrm{a}}$ \\
\hline 1 & Yes & 282 & 47.9 & 73.0 & 11.7 & 53 \\
2 & Yes & 61 & 52.5 & 75.4 & 16.4 & 66 \\
3 & Yes & 110 & 40.0 & 60.9 & $\mathrm{n} / \mathrm{a}$ & 62 \\
4 & No & 114 & 47.4 & 93.0 & 24.6 & 65 \\
5 & Yes & 112 & 50.0 & 83.0 & 15.2 & 72 \\
6 & Yes & 121 & 47.1 & 90.1 & 19.8 & 71 \\
7 & No & 53 & 41.5 & 92.5 & 18.9 & 33 \\
8 & Yes & 105 & 46.7 & 78.1 & 10.5 & 57 \\
9 & No & 71 & 45.1 & 81.7 & 19.7 & 45 \\
10 & Yes & 84 & 33.3 & 72.6 & 4.8 & 95 \\
11 & No & 183 & 44.8 & 65.0 & 17.5 & 61 \\
12 & No & 239 & 51.0 & 48.5 & 13.0 & 84 \\
13 & No & 197 & 49.2 & 90.4 & 11.7 & 66 \\
14 & No & 50 & 48.0 & 88.0 & 16.0 & 39 \\
15 & No & 108 & 51.9 & 80.6 & 15.7 & 46 \\
\hline
\end{tabular}

One school did not provide Special Education ("Special Ed") status

a State records 
these concepts in small groups and taught one another. In addition to the different types of positive interdependence, strategies were presented to support the concept of individual accountability, and teachers were also trained to deliver explicit coaching in collaborative group social skills, to support a high degree of face-to-face interaction among students during the cooperative lessons, and to set aside time at the conclusion of the lesson to support the guided processing of group performance. At the conclusion of each training session, the trainers discussed how the lesson structure reflected the foundational concepts of cooperative learning, providing teachers with insight into how these concepts could be applied in their own teaching, as well as giving them a clear sense of what it feels like to participate in a cooperative learning lesson.

In addition to the foundational concepts of cooperative learning, teachers were also given specific lesson formats that adhere to these concepts, including the jigsaw lesson (discussed above) and similar formats, including reciprocal teaching, peer tutoring, collaborative reading, and other methods in which peers help each other learn in small groups under conditions of positive interdependence. Finally, teachers were provided the opportunity to develop draft lesson plans which they could use to deliver cooperative learning lessons in their own classroom. We did not have specific targets or goals for teachers regarding their use of cooperative learning, but rather asked them to make use of these techniques in their classrooms as often as they were able, and in a manner that suited their curriculum and teaching style.

To be successful in convincing teachers to make use of these techniques, administrator support was critical. Administrators participated in the vast majority of the teacher training sessions, and were also provided a targeted workshop during the summer as discussed above. We brought the administrative teams from each of our intervention schools together for a single day where they were given a review of the foundational concepts of cooperative learning as well as ways in which they could support their staff in using cooperative learning through observation, sharing of concepts and experiences among staff, and dedicated collective planning time. Administrators were also encouraged to apply cooperative learning techniques to staff management and professional development to promote increased cooperation among teachers. Each administrator was given a copy of Leading the Cooperative School (Johnson and Johnson 1994), which was the basis for the training.

\subsection{Measures}

Student data collection was conducted in September/October and March/April of the 2016-2017 and 2017-2018 school years (4 waves in total) using on-line surveys (Qualtrics; https:/www.qualtrics.com/). A Certificate of Confidentiality was obtained for these data from NIAAA (\#CC-AA-17-011). To shrink the overall number of items and reduce participant burden, existing data from other studies were used to select the highest-loading items from each scale below (additional information available from the first author).

To assess fidelity of implementation, we also conducted teacher observations. Observations were conducted once in the late fall/early winter and again in the spring of the first year. Observers remained in a classroom for an entire class period. Teachers were selected at random in each school, and 5-7 teachers were observed during each school visit. 
Prosocial Behavior We used three items from the Prosocial Behavior subscale of the Strengths and Difficulties Questionnaire (Goodman et al. 1998), which has been used extensively in studies of adolescents (Muris et al. 2003; Van Roy et al. 2008). Items included "I usually share with others", "I often offer to help others (parents, teachers, other students)", and "I try to be nice to other people; I care about their feelings". Students responded on a 3-point scale from 1 (Not true) to 3 (Certainly true). Items were averaged to arrive at the scale score. Alpha reliability ranged from .70 to .81 across waves 1 to 4 .

Peer Relatedness We used 4 items from the Relatedness Scale, which has been used in previous research as a predictor of positive school adjustment in adolescents (Furrer and Skinner 2003). Items included a common stem ("When I'm with my classmates..."), and the following phrases: "I feel accepted", "I feel ignored" (reverse scored), "I feel like someone special", and "I feel unimportant" (reverse scored). Students responded on a 4-point scale from 1 (Not at all true) to 4 (Very true). Items were averaged to arrive at the scale score. Alpha reliability was .71 at wave 1 and .79 at wave 2 .

Demographics Sex was collected from school records and coded as Male (0) and Female (1).

Observed Intervention Fidelity Research staff blind to intervention assignment observed teaching practices in intervention and control schools. Dr. Roseth trained our observers using prototypical (simulated) classroom situations before they were permitted to conduct observations in actual classrooms. We used three observers, all of whom had BS or BA degrees and some experience with observational protocols. We used an established observation protocol that coded for the presence or absence of key aspects of cooperative learning (e.g., positive interdependence; Krol et al. 2008; Veenman et al. 2002). For example, forms of positive interdependence were counted, and a total was assigned to each lesson; a lesson involving nothing but lecture and/or individual seatwork would have no positive interdependence, and thus would be coded as zero.

Training took place over the Internet and included a presentation of the protocol, including the various dimensions that were to be coded (e.g., positive interdependence), and a discussion of how to code various prototypical classroom situations. Training was concluded when trainee codes demonstrated complete agreement with the trainer.

\subsection{Analysis Plan}

Our research questions involved a test of mediation, which traditionally includes an initial direct-effects model that tests the path between the predictor and outcome (commonly referred to as "path c"), followed by a mediation model in which the following paths are tested: the predictor to the presumed mediator ("path a"), the mediator to the outcome ("path b"), and the combined indirect effect of the predictor on the outcome via the mediator, while controlling for the direct effect (commonly referred to as "path c"", or "path c-prime"; Judd, Kenny, \& McClelland, 2001; MacKinnon \& Dwyer, 1993). 
Thus, we initially tested a direct-effects model for prosocial behavior (referenced in the Results section as Model 1). We used all four waves of measurement in a latent growth curve and evaluated intervention effects on the linear slope (i.e., the change in prosocial behavior during the project). Next, we added peer relatedness to the model as a mediator of intervention effects on prosocial behavior, and tested the indirect pathway (referenced as Model 2). We used peer relatedness from wave 2, controlling for wave 1 (baseline) levels, to represent change during the first school year. The full model (i.e., Model 2) is presented in Fig. 1.

In addition to the key model paths presented in Fig. 1, the linear growth curve slope for prosocial behavior was regressed on the corresponding intercept term, and the intercept term (and T1 scores for peer relatedness) were allowed to correlate with the intervention condition. We controlled for the effects of sex throughout the model, given existing research on sex differences in prosocial behavior (Eagly 2009).

We fit these models and calculated the significance of the indirect effect using Mplus 7.4 (Muthén and Muthén 1998-2012) and Maximum Likelihood (ML) estimation with robust standard errors, which can provide unbiased estimates in the presence of missing data and/or non-normal distributions (Enders and Bandalos 2001). Mplus also enabled us to account for the nesting in the data and calculate appropriate standard errors; however, sample size limitations prevented us from including random effects in the model, so all effects were fixed. For each model, standard measures of fit are reported, including the chi-square $\left(\chi^{2}\right)$, comparative fit index (CFI), nonnormed or Tucker-Lewis index (TLI), and root mean square error of approximation (RMSEA). CFI values greater than .95, TLI values greater than .90, and RMSEA values less than .05 indicate good fit (Bentler 1990; Hu and Bentler 1999).

\section{Results}

Descriptive data for all variables and correlations are presented in Table 2. ANOVA models indicated that students in intervention and control schools did not differ in terms of baseline levels of prosocial behavior $[F(1,1455)=.00, n s]$ or peer relatedness

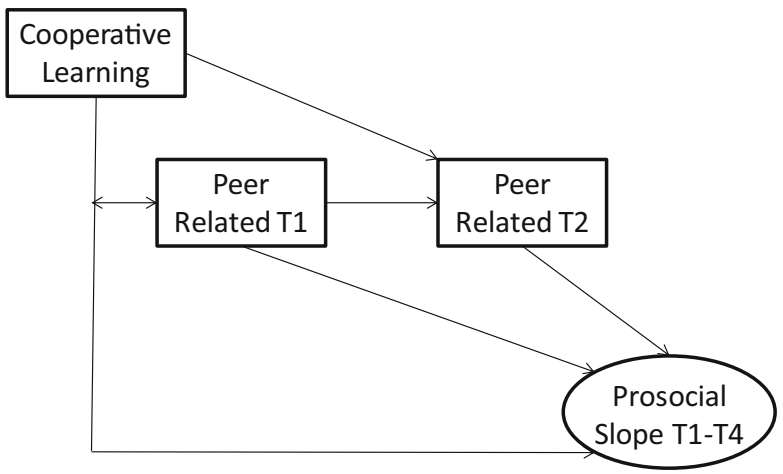

Fig. 1 Full model. Peer Related = Peer Relatedness. Latent construct is linear growth curve slope for prosocial behavior; the model also included intercept term (not pictured), which were allowed to correlate freely with the intervention condition (i.e., cooperative learning). Baseline (T1) levels of Peer Relatedness were also allowed to correlate with the intervention condition. Sex was controlled throughout the model (not pictured) 
Table 2 Correlations and descriptive data

\begin{tabular}{|c|c|c|c|c|c|c|c|}
\hline & 1 & 2 & 3 & 4 & 5 & 6 & 7 \\
\hline 1. Sex & - & & & & & & \\
\hline 2. Peer relatedness (Wave 1) & $-.05^{*}$ & - & & & & & \\
\hline 3. Peer relatedness (Wave 2) & $-.11^{* * * *}$ & $.50^{* * *}$ & - & & & & \\
\hline 4. Prosocial behavior (Wave 1) & $.10^{* * * *}$ & $.26^{* * *}$ & $.15^{* * *}$ & - & & & \\
\hline 5. Prosocial behavior (Wave 2) & $.13^{* * *}$ & $.14^{* * *}$ & $.30^{* * * *}$ & $.47^{* * * *}$ & - & & \\
\hline 6. Prosocial behavior (Wave 3 ) & $.10^{* * *}$ & $.10^{* *}$ & $.11^{* * *}$ & $.33^{* * *}$ & $.42^{* * *}$ & - & \\
\hline 7. Prosocial behavior (Wave 4) & $.12^{* * * *}$ & $.13^{* * * *}$ & $.14^{* * *}$ & $.30^{* * * *}$ & $.36^{* * *}$ & $.47^{* * * *}$ & - \\
\hline$N$ & 1856 & 1447 & 1513 & 1457 & 1533 & 1571 & 1480 \\
\hline$M$ & .48 & 3.07 & 2.98 & 2.54 & 2.46 & 2.42 & 2.38 \\
\hline$S D$ & .50 & .68 & .76 & .43 & .50 & .51 & .55 \\
\hline
\end{tabular}

${ }^{*} p<.05 .{ }^{* *} p<.01 .{ }^{* * *} p<.001$

$[F(1,1445)=.04, n s]$. With regard to fidelity observations, ANOVA indicated significantly higher levels of observed positive interdependence in intervention schools as compared to control schools, $F(1,98)=10.79, p<.01, R^{2}=.10$. Fidelity observations at baseline demonstrated no differences, $F(1,99)=1.41$, $n s$.

We first evaluated the direct effects of cooperative learning on change in prosocial behavior (i.e., path c), controlling for the effects of sex. Model fit was adequate, $\chi^{2}(10)=10.90, n s ;$ CFI $=1.00 ;$ TLI $=1.00 ;$ RMSEA $=.007$ (90\% C.I.: .000-.026). Results are provided in Table 3 (see Model 1). Intervention effects were significant and moderate, and females demonstrated larger intercepts and slopes of prosocial behavior.

We next evaluated intervention effects with the mediator (i.e., peer relatedness) included. Model fit was adequate, $\chi^{2}(16)=76.85, p<.001 ; \mathrm{CFI}=.98$; TLI $=.96$; RMSEA $=.045$ (90\% C.I.: .035-.055). Results are provided in Table 3 (see Model 2 ). The effect of cooperative learning on change in peer relatedness was significant, and the indirect effect of cooperative learning on change in prosocial behavior by means of peer relatedness was significant (standardized effect $=.02, p<.05$ ). The effect of sex on peer relatedness indicated that females were slightly lower at the end of the first year (T2). Interestingly, the direct effect of cooperative learning on change in prosocial behavior remained significant, indicating that the mediator was only partly responsible for transmitting the effects of the intervention on the outcome.

\section{Discussion}

Although cooperative learning possesses robust empirical evidence supporting its ability to encourage interpersonal attraction, social acceptance, and academic motivation and achievement (Ginsburg-Block et al. 2006; Johnson et al. 2014; Roseth et al. 2008), it has not yet been formally tested for its ability to promote prosocial behavior. In this study, we found that cooperative learning can promote growth in prosocial behavior over two school years, with a moderate effect size. We also found that the 
Table 3 Model effects

\begin{tabular}{lcc}
\hline Model path & Model 1 & Model 2 \\
\hline Cooperative learning $\rightarrow$ Prosocial Behavior (Slope) & $.33^{* * * *}$ & $.30^{* * *}$ \\
Sex $\rightarrow$ Prosocial Behavior (Intercept) & $.11^{* *}$ & $.12^{* *}$ \\
Sex $\rightarrow$ Prosocial Behavior (Slope) & $.13^{* * *}$ & $.13^{* * *}$ \\
Cooperative learning $\rightarrow$ Peer Relatedness (T2) & $.10^{* *}$ \\
Sex $\rightarrow$ Peer Relatedness (T2) & $-.08^{*}$ \\
Peer Relatedness (T1) $\rightarrow$ Peer Relatedness (T2) & $.51^{* * *}$ \\
Peer Relatedness (T2) $\rightarrow$ Prosocial Behavior (Slope) & $.19^{* * *}$ \\
\hline
\end{tabular}

${ }^{*} p<.05 .{ }^{* *} p<.01 .{ }^{* * *} p<.001$

effects on prosocial behavior were mediated by peer relatedness, suggesting that more positive peer relationships can support greater prosocial behavior. This latter finding was particularly important, as this aspect of Social Interdependence Theory (Deutsch 1949, 1962) has been hypothesized but not empirically tested.

We found sex differences in both prosocial behavior and peer relatedness. Females reported greater growth in prosocial behavior during the year, which echoes previous research (Burton et al. 2007; Eagly 2009). This is hypothesized to reflect evolutionary tendencies for women to focus on behavior that supports the creation and maintenance of relationships during this developmental period. Regarding the sex differences in peer relatedness, the lower growth reported by females may reflect the existence of relational aggression, which is higher among adolescent women, particularly in middle school (Archer and Coyne 2005; Crick and Grotpeter 1995). Alternatively, it may reflect higher levels of depressive symptoms among adolescent women, which is also particularly prevalent during this developmental period as they enter puberty and begin to struggle with issues such as self-esteem and body image (Hankin et al. 1998; Marcotte et al. 2002).

\subsection{Implications for Research}

These results have several implications for future research. First, we hypothesized that the emphasis in cooperative learning on peer reinforcement for positive behavior contributed to both an improvement in peer relations and an increase in prosocial behavior, but it is possible that the relationship between peer relatedness and prosocial behavior could be bidirectional rather than unidirectional as we have tested here. Further research could evaluate longitudinal links between these two constructs, potentially with a cross-lagged latent change score model (McArdle 2009), which can assess the directionality of effects across time.

Second, our results also indicated that mediation was only partial. Although some have cautioned against using the term "partial mediation" due to its dependence on statistical significance and, in turn, on sample size (Little et al. 2007), we feel it is important to note that cooperative learning had significant effects on change in prosocial behavior even with the mediator (i.e., peer relations) in the model. Our results therefore provide only partial support for the hypothesis that cooperative learning 
effects are mediated by the quality of peer relations, and we must acknowledge that additional mechanisms may be involved. For example, cooperative learning may have contributed to a shift in behavioral norms among students. By establishing positive interdependence, cooperative learning motivates students to help each other and share resources and information, which in turn re-orients behavioral norms in favor of positive, helpful behavior (O'Donnell and O'Kelly 1994). Likewise, teachers' explicit instruction in and reinforcement for positive behavior during learning activities may also have contributed to an increased frequency in prosocial behavior. The independent and joint contributions of these processes should be explored in future research.

\subsection{Implications for Instruction}

These results also have several implications for instruction. First, we note that cooperative learning is not a set curriculum but rather is an instructional technique that can be applied to any subject at any grade level (see Ginsburg-Block et al. 2006; Johnson et al. 2014; Roseth et al. 2008) without requiring the sacrifice of instructional time to make room for a separate curriculum, as is required in many current SEL programs. The peer reinforcement for positive behavior that occurs during cooperative learning has also been found to reduce alcohol/tobacco use and bullying/victimization in middle school (Van Ryzin and Roseth 2018a, b, c), suggesting that schools implementing cooperative learning may realize widespread improvements in student behavior in addition to the anticipated gains in student motivation and achievement. In other words, schools may be able to obtain the benefits of prevention and SEL programs without having to incur the associated costs for curricula, teacher training, and loss of instructional time.

Second, our results suggest that the effects of cooperative learning on behavior are realized through the experience of working in groups, rather than through direct instruction in social-emotional content or bullying/drug use prevention. This suggests that greater use of cooperative learning may yield greater positive effects on student behavior. However, we note that this study used a sample of middle school students, and thus we are not able to extend these results to instructional practices in elementary or high school.

We also note that, anecdotally, the teachers in our sample did have some difficulty in mastering small-group instructional techniques. These difficulties fell into one of two areas: design fidelity (i.e., ensuring that all the key components were included in a lesson design); and, lesson delivery (i.e., ensuring that the lesson was completed during the class period). We would advocate for instructional technology as a means to support teachers in meeting these challenges.

\subsection{Limitations}

This research is limited in four key ways. First, it is based upon a relatively homogeneous sample of rural students that was about three-quarters White, which limits the external validity (generalizability) of the results. Second, all measures were self-report, and in some cases had lower reliability, which limits internal validity. Future research should consider additional data sources, such as teachers and/or parents, and more diverse populations. Third, the small number of schools in our sample (15) limited the complexity of the models that we were able to fit to the data, so we were unable to 
explore moderators of effects (e.g., whether effects were stronger among more marginalized students). Future research should examine these mechanisms in more detail. Finally, as noted above, we have presented peer relatedness as a mediator of effects on prosocial behavior, but we freely acknowledge that the two variables could have a reciprocal relationship; future research should explore this possibility.

\section{Conclusion}

The results of this cluster randomized trial extend prior research on cooperative learning by demonstrating that it not only promotes academic achievement, but also promotes prosocial behavior among middle school students. In addition, we also found that these effects were partially mediated by improvements in peer relations. We hope that the results reported here contribute to a renewed interest in cooperative learning as an instructional approach that can be implemented as a core aspect of teacher training and professional development.

Acknowledgements The National Institute on Alcohol Abuse and Alcoholism (NIAAA) provided financial support this project (R34 AA024275; PI: M. J. Van Ryzin). Support for the third author also provided by NIAAA (R01 AA021726; PI: A. Biglan). The content of this manuscript is solely the responsibility of the authors and does not necessarily represent the official views of NIAAA or the National Institutes of Health.

\section{Compliance with Ethical Standards}

Conflict of Interest The authors declare that they have no conflict of interest.

Ethical Approval This article does not contain any studies with animals.

Consent We used a passive consent procedure for the student data collection.

\section{References}

Allport, G. W. (1954). The nature of prejudice. Garden City: Doubleday.

Archer, J., \& Coyne, S. M. (2005). An integrated review of indirect, relational, and social aggression. Personality and Social Psychology Review, 9, 212-230. https://doi.org/10.1207/s15327957pspr0903_2.

Aronson, E., \& Bridgeman, D. (1979). Jigsaw groups and the desegregated classroom: In pursuit of common goals. Personality and Social Psychology Bulletin, 5, 438-446. https://doi.org/10.1177 /014616727900500405.

Bentler, P. M. (1990). Comparative fit indexes in structural models. Psychological Bulletin, 107, 238-246. https://doi.org/10.1037/0033-2909.107.2.238.

Bierman, K. L. (2004). Peer rejection: Developmental processes and intervention. New York: Guilford Publications.

Biglan, A. (2015). The nurture effect: How the science of human behavior can improve our lives and our world. Oakland: New Harbinger.

Burton, L. A., Hafetz, J., \& Henninger, D. (2007). Gender differences in relational and physical aggression. Social Behavior and Personality, 35, 41-50.

Caprara, G. V., Kanacri, B. P. L., Gerbino, M., Zuffiano, A., Alessandri, G., Vecchio, G., et al. (2014). Positive effects of promoting prosocial behavior in early adolescence: Evidence from a school-based intervention. International Journal of Behavioral Development, 38(4), 386-396. https://doi.org/10.1177 $/ 0165025414531464$. 
Craig, W., Harel-Fisch, Y., Fogel-Grinvald, H., Dostaler, S., Hetland, J., Simons-Morton, B., et al. (2009). A cross-national profile of bullying and victimization among adolescents in 40 countries. International Journal of Public Health, 54, 216-224. https://doi.org/10.1007/s00038-009-5413-9.

Crick, N. R., \& Grotpeter, J. K. (1995). Relational aggression, gender, and social-psychological adjustment. Child Development, 66, 710-722. https://doi.org/10.1111/j.1467-8624.1995.tb00900.x.

Deutsch, M. (1949). A theory of cooperation and competition. Human Relations; Studies Towards the Integration of the Social Sciences, 2, 129-151.

Deutsch, M. (1962). Cooperation and trust: Some theoretical notes. In M. Jones (Ed.), Nebraska symposium on motivation (pp. 275-319). Lincoln: University of Nebraska Press.

Dovidio, J. F., Gaertner, S. L., \& Saguy, T. (2009). Commonalty and the complexity of 'we': Social attitudes and social change. Personality and Social Psychology Review, 13, 3-20. https://doi.org/10.1177 $/ 1088868308326751$.

Durlak, J. A., Weissberg, R. P., Dymnicki, A. B., Taylor, R. D., \& Schellinger, K. B. (2011). The impact of enhancing students' social and emotional learning: A meta-analysis of school-based universal interventions. Child Development, 82, 405-432. https://doi.org/10.1111/j.1467-8624.2010.01564.x.

Eagly, A. H. (2009). The his and hers of prosocial behavior: An examination of the social psychology of gender. The American Psychologist, 64, 644-658. https://doi.org/10.1037/0003-066X.64.8.644.

Enders, C. K., \& Bandalos, D. L. (2001). The relative performance of full information maximum likelihood estimation for missing data in structural equation models. Structural Equation Modeling, 8, 430-457. https://doi.org/10.1207/S15328007SEM0803 5.

Farrington, D. P. (2005). The importance of child and adolescent psychopathy. Journal of Abnormal Child Psychology, 33, 489-497. https://doi.org/10.1007/s10802-005-5729-8.

Ferguson, C. J., Miguel, C. S., Kilburn Jr., J. C., \& Sanchez, P. (2007). The effectiveness of school-based antibullying programs: A meta-analytic review. Criminal Justice Review, 32, 401-414. https://doi. org/10.1177/0734016807311712.

Furrer, C., \& Skinner, E. (2003). Sense of relatedness as a factor in children's academic engagement and performance. Journal of Education \& Psychology, 95, 148-162. https://doi.org/10.1037/00220663.95.1.148.

Ginsburg-Block, M. D., Rohrbeck, C. A., \& Fantuzzo, J. W. (2006). A meta-analytic review of social, selfconcept, and behavioral outcomes of peer-assisted learning. Journal of Education \& Psychology, 98, 732749. https://doi.org/10.1037/0022-0663.98.4.732.

Goodman, R., Meltzer, H., \& Bailey, V. (1998). The strengths and difficulties questionnaire: A pilot study on the validity of the self-report version. European Child \& Adolescent Psychiatry, 7, 125-130. https://doi. org/10.1007/s007870050057.

Hankin, B. L., Abramson, L. Y., Moffitt, T. E., Silva, P. A., McGee, R., \& Angell, K. E. (1998). Development of depression from preadolescence to young adulthood: Emerging gender differences in a 10-year longitudinal study. Journal of Abnormal Psychology, 107(1), 128-140. https://doi.org/10.1037/0021843X.107.1.128.

Hu, L., \& Bentler, P. M. (1999). Cutoff criteria for fit indexes in covariance structure analysis: Conventional criteria versus new alternatives. Structural Equation Modeling, 6, 1-55. https://doi.org/10.1080 /10705519909540118.

Johnson, D. W. (2003). Social interdependence: Interrelationships among theory, research, and practice. The American Psychologist, 58, 934-945. https://doi.org/10.1037/0003-066X.58.11.934.

Johnson, D. W., \& Johnson, R. (1989). Cooperation and competition: Theory and research. Edina: Interaction Book Company.

Johnson, D. W., \& Johnson, R. T. (1994). Leading the cooperative school. Edina: Interaction Book Company.

Johnson, D. W., \& Johnson, R. T. (2005). New developments in social interdependence theory. Genetic, Social, and General Psychology Monographs, 131, 285-358.

Johnson, D. W., Johnson, R. T., \& Maruyama, G. (1983). Interdependence and interpersonal attraction among heterogeneous and homogeneous individuals: A theoretical formulation and a meta-analysis of the research. Review of Educational Research, 53, 5-54. https://doi.org/10.3102/00346543053001005.

Johnson, D. W., Johnson, R., \& Holubec, E. (2013). Cooperation in the classroom (9th ed.). Edina: Interaction Book Company.

Johnson, D. W., Johnson, R. T., Roseth, C. J., \& Shin, T.-S. (2014). The relationship between motivation and achievement in interdependent situations. Journal of Applied Social Psychology, 44, 622-633. https://doi. org/10.1111/jasp.12280.

Judd, C. M., Kenny, D. A., \& McClelland, G. H. (2001). Estimating and testing mediation and moderation in within-subject designs. Psychological Methods, 6, 115-134. 
Krol, K., Sleegers, P., Veenman, S., \& Voeten, M. (2008). Creating cooperative classrooms: Effects of a twoyear staff development program. Educational Studies, 34, 343-360. https://doi.org/10.1080 /03055690802257101.

Little, T. D., Card, N. A., Bovaird, J. A., Preacher, K. J., \& Crandall, C. S. (2007). Structural equation modeling of mediation and moderation with contextual factors. In T. D. Little, J. A. Bovaird, \& N. A. Card (Eds.), Modeling contextual effects in longitudinal studies (pp. 207-230). Mahwah: Lawrence Erlbaum Associates.

MacKinnon, D. P., \& Dwyer, J. H. (1993). Estimating mediated effects in prevention studies. Evaluation Review, 17, 144-158.

Marcotte, D., Fortin, L., Potvin, P., \& Papillon, M. (2002). Gender differences in depressive symptoms during adolescence: Role of gender-typed characteristics, self-esteem, body image, stressful life events, and pubertal status. Journal of Emotional and Behavioral Disorders, 10(1), 29-42. https://doi.org/10.1177 /106342660201000104.

McArdle, J. J. (2009). Latent variable modeling of differences and changes with longitudinal data. Annual Review of Psychology, 60, 577-605. https://doi.org/10.1146/annurev.psych.60.110707.163612.

Merrell, K. W., Gueldner, B. A., Ross, S. W., \& Isava, D. M. (2008). How effective are school bullying intervention programs? A meta-analysis of intervention research. School Psychology Quarterly, 23, 2642. https://doi.org/10.1037/1045-3830.23.1.26.

Muris, P., Meesters, C., \& van den Berg, F. (2003). The strengths and difficulties questionnaire (SDQ). European Child \& Adolescent Psychiatry, 12(1), 1-8. https://doi.org/10.1007/s00787-003-0298-2.

Muthén, L. K., \& Muthén, B. O. (1998-2012). Mplus User's Guide (7th ed.). Los Angeles: Muthén \& Muthén.

O'Donnell, A. M., \& O'Kelly, J. (1994). Learning from peers: Beyond the rhetoric of positive results. Educational Psychology Review, 6, 321-349. https://doi.org/10.1007/BF02213419.

Pettigrew, T. F. (1998). Intergroup contact theory. Annual Review of Psychology, 49, 65-85. https://doi. org/10.1146/annurev.psych.49.1.65.

Pettigrew, T. F., \& Tropp, L. R. (2000). Does intergroup contact reduce prejudice? Recent meta-analytic findings. In S. Oskamp (Ed.), Reducing prejudice and discrimination: Social psychological perspectives (pp. 93-114). Mahwah: Erlbaum.

Pettigrew, T. F., \& Tropp, L. R. (2008). How does intergroup contact reduce prejudice? Meta-analytic tests of three mediators. European Journal of Social Psychology, 38, 922-934. https://doi.org/10.1002/ejsp.504.

Pool, A. C., Patterson, F., Luna, I. Y., Hohl, B., \& Bauer, K. W. (2017). Ten-year secular trends in youth violence: Results from the Philadelphia youth risk behavior survey 2003-2013. The Journal of School Health, 87, 244-252. https://doi.org/10.1111/josh.12491.

Roseth, C. J. (2016). Character education, moral education, and moral-character education. In L. Corno \& E. M. Anderman (Eds.), Handbook of educational psychology (3rd ed.). New York: Routledge/TaylorFrancis.

Roseth, C. J., Johnson, D. W., \& Johnson, R. T. (2008). Promoting early adolescents' achievement and peer relationships: The effects of cooperative, competitive, and individualistic goal structures. Psychological Bulletin, 134, 223-246. https://doi.org/10.1037/0033-2909.134.2.223.

Schwartz, S. J., Phelps, E., Lerner, J. V., Huang, S., Brown, C. H., Lewin-Bizan, S., et al. (2010). Promotion as prevention: Positive youth development as protective against tobacco, alcohol, illicit drug, and sex initiation. Applied Developmental Science, 14, 197-211. https://doi.org/10.1080/10888691.2010.516186.

Silberman, M. (1996). Active learning: 101 strategies to teach any subject. Boston: Allyn and Bacon.

Taylor, R. D., Oberle, E., Durlak, J. A., \& Weissberg, R. P. (2017). Promoting positive youth development through school-based social and emotional learning interventions: A meta-analysis of follow-up effects. Child Development, 88, 1156-1171. https://doi.org/10.1111/cdev.12864.

Topping, K. J. (2005). Trends in peer learning. Educational Psychologist, 25, 631-645. https://doi.org/10.1080 /01443410500345172.

Ttofi, M. M., \& Farrington, D. P. (2011). Effectiveness of school-based programs to reduce bullying: A systematic and meta-analytic review. Journal of Experimental Criminology, 7, 27-56. https://doi. org/10.1007/s11292-010-9109-1.

Van Roy, B., Veenstra, M., \& Clench-Aas, J. (2008). Construct validity of the five-factor Strengths and Difficulties Questionnaire (SDQ) in pre-, early, and late adolescence. Journal of Child Psychology and Psychiatry, 49, 1304-1312. https://doi.org/10.1111/j.1469-7610.2008.01942.x.

Van Ryzin, M. J., \& Roseth, C. J. (2018a). Enlisting peer cooperation in the service of alcohol use prevention in middle school. Child Development, 89, e459-e467. https://doi.org/10.1111/cdev.12981.

Van Ryzin, M. J., \& Roseth, C. J. (2018b). Cooperative learning in middle school: A means to improve peer relations and reduce victimization, bullying, and related outcomes. Journal of Education \& Psychology, 110, 1192-1201. https://doi.org/10.1037/edu0000265. 
Van Ryzin, M. J., \& Roseth, C. J. (2018c). Peer influence processes as mediators of effects of a middle school substance use prevention program. Addictive Behaviors, 85, 180-185. https://doi.org/10.1016/j. addbeh.2018.06.016.

Veenman, S., van Benthum, N., Bootsma, D., van Dieren, J., \& van der Kemp, N. (2002). Cooperative learning and teacher education. Teaching and Teacher Education, 18, 87-103. https://doi.org/10.1016 /S0742-051X(01)00052-X.

Wilson, D. S. (2007). Evolution for everyone: How Darwin's theory can change the way we think about our lives. New York: Delacorte Press.

Wilson, D. S. (2002). Darwin's cathedral: Evolution, religion, and the nature of society. Chicago: University of Chicago Press.

Wilson, D. S. (2015). Does altruism exist? Culture, genes, and the welfare of others. New Haven: Yale University Press.

World Health Organization. (2012). Risk behaviours: Being bullied and bullying others. In C. Currie et al. (Eds.), Social determinants of health and well-being among young people. Health behaviour in schoolaged children (HBSC) study: International report from the 2009/2010 survey (pp. 191-200). WHO Regional Office for Europe: Copenhagen.

Publisher's Note Springer Nature remains neutral with regard to jurisdictional claims in published maps and institutional affiliations. 